\title{
As amenidades naturais influenciam a escolha locacional dos trabalhadores? Evidências para as regiões metropolitanas brasileiras
}

\author{
Roberta de Moraes Rocha* \\ André Matos Magalhães**
}

\begin{abstract}
O artigo apresenta evidências da importância das características naturais das regiões metropolitanas brasileiras para as escolhas locacionais dos trabalhadores. A análise baseia-se no modelo de escolha locacional de Roback (1982), a partir do qual é derivado o valor que os trabalhadores atribuem para morar em localidades que Ihe ofertem um bom consumo de amenidades naturais. Os principais resultados da pesquisa indicam que os trabalhadores estão dispostos a pagar para morar nas RMs mais próximas à costa, com os maiores índices médios anuais de precipitação, nas RMs mais úmidas, e com as maiores temperaturas médias no mês de janeiro. Por outro lado, os trabalhadores devem ser compensados monetariamente para morar nas RMs com os maiores índices médios de precipitação em setembro e com as maiores temperaturas médias em julho.
\end{abstract}

Palavras-chaves: Valoração das amenidades. Abordagem hedônica. Qualidade das amenidades naturais.

\section{Introdução}

Em decorrência do crescimento e desenvolvimento das cidades, pesquisadores regionais e urbanos, interessados em mensurar a importância atribuída pelos trabalhadores ao consumo das amenidades locais, vêm aplicando a abordagem hedônica ${ }^{1}$ como instrumento para valoração das amenidades locais (ROSEN, 1979; ROBACK, 1980; 1982; BLOMQUIST et al., 1988; GYOURKO; TRACY, 1991).

Nesse contexto, quando o objetivo de análise é a valoração das amenidades locais, a mesma ideia da abordagem hedônica, aplicada a produtos heterogêneos, ${ }^{2}$ é imposta às unidades geográficas de análise, já que são caracterizadas por um conjunto de atributos locais diferenciados. Porém, como as amenidades locais não possuem preço de mercado, o valor que as pessoas estão dispostas a pagar por elas, a partir da abordagem hedônica, é obtido indiretamente, em função das escolhas locacionais dos indivíduos, do preço que os consumidores estão propensos a pagar pela habitação e/ ou do salário recebido na localidade ${ }^{3}$ onde

\footnotetext{
* Professora Dra. do Programação de Pós-Graduação em Economia da UFPE-CAA (PPGECON) e do Curso de Economia - Núcleo de Gestão do CAA.

** Professor Dr. do Programa de Pós-Graduação em Economia da UFPE (Pimes) e do Curso de Economia - Decon.

1 Gyourko et al. (1997) fazem um revisão dos modelos hedônicos aplicados para a valoração das amenidades.

2 A abordagem hedônica tem uma tradicional aplicação em estudos que objetivam estimar o preço de produtos heterogêneos em função das características do produto, como, por exemplo, os automóveis, imóveis ou outro produto qualquer que possa ser representado por um conjunto de atributos (ROSEN, 1974, CROPPER et al., 1993, JONKER, 2002). ${ }^{3}$ De forma genérica, o termo "localidade" no texto está sendo empregado para se referir a qualquer unidade geográfica de análise. Contudo, sabe-se que o IBGE define a localidade como "todo lugar do território nacional onde existe um aglomerado permanente de habitantes".
} 
residem (ROSEN, 1974; 1979; ROBACK, 1980; 1982).

Assumi-se, portanto, que o consumidor, ao escolher um imóvel para residir, está escolhendo simultaneamente o conjunto de amenidades - atributos locais que influenciam no preço do imóvel - que irá consumir e, portanto, no preço do imóvel deve estar embutido o valor que ele atribui ao consumo das amenidades (ROSEN, 1974). De forma alternativa, Rosen (1979) parte da suposição de que a escolha locacional dos trabalhadores depende, entre outros fatores, do salário que a localidade oferece e dos atributos locais. Assim, supondo-se que ambos, as amenidades e o salário, são fatores de atração dos trabalhadores, tem-se que a remuneração do capital humano em cada região também pode informar sobre as preferências dos consumidores pelas amenidades.

Unindo os dois mercados - o de trabaIho e o de habitação -, pode-se dizer que Roback $(1980,1982)$, com a inclusão do mercado de produção no modelo de Rosen (1979), fornece pioneiramente um indicador que mensura o valor que as pessoas estão propensas a pagar pelas amenidades, com base em um modelo de escolha locacional. A autora, a partir da propensão marginal a pagar pelas amenidades, constrói uma medida para avaliar a qualidade das amenidades das regiões, a qual nomeia de "índice de qualidade de vida local".

Tomando como referência o modelo de Roback (1982), este artigo tem como objetivo principal apresentar evidências da importância das características naturais das regiões metropolitanas para a escolha locacional dos trabalhadores. Desse modo, a partir da abordagem hedônica, estima-se a propensão marginal a pagar por estes atributos locais, indicando o valor monetário que os trabalhadores estão dispostos a pagar por eles; e, com base nesta informação, calculam-se índices de qualidade das amenidades locais. A análise é realizada para as nove principais regiões metropoli- tanas brasileiras: Belém, Fortaleza, Recife, Salvador, Belo Horizonte, Rio de Janeiro, São Paulo, Curitiba e Porto Alegre.

Esta pesquisa justifica-se pela falta de evidências empíricas, para o Brasil, a respeito da importância das amenidades locais para a escolha locacional dos trabalhadores e da influência destes fatores na função de bem-estar deles. Também a pesquisa em torno das amenidades naturais ${ }^{4}$ justifica-se, em primeiro lugar, pela importância dos fatores climáticos para o bem-estar dos trabalhadores e, ainda, pela falta de evidências empíricas, para o Brasil, da relação entre as amenidades naturais, o bem-estar e a escolha locacional dos agentes produtivos.

Este tema torna-se ainda mais relevante quando se observam localidades que podem deixar de ser habitadas devido às suas características naturais. Neste contexto, citam-se, por exemplo, as consequências das mudanças climáticas e seus efeitos para o meio ambiente e para as escolhas locacionais dos indivíduos. Em decorrência desse fato, defende-se a proposição de que os fatores climáticos das regiões de um país, que devem possuir diferentes características - considerando-se que esta heterogeneidade pode ter diversas magnitudes -, além de impactar de forma diferenciada no meio ambiente, também podem atuar como fatores de aglomeração da população para as regiões que ofereçam condições climáticas mais agradáveis. Ou melhor, dando força para a relação entre o clima e o bem-estar, pois sabe-se que o clima pode influenciar na qualidade da saúde dos seres humanos, o qual, em situações extremas, pode levar à proliferação de epidemias e de doenças respiratórias e até à morte dos indivíduos. ${ }^{5}$

Além dessa introdução, o artigo está estruturado com uma seção que apresenta o modelo empírico de Roback (1982) e estudos empíricos que abordam o tema. A terceira seção é destinada à da base de dados e aos modelos empíricos estimados. Posteriormente, são analisados os resulta-

\footnotetext{
${ }^{4}$ Amenidades naturais ou puras correspondem àquelas que não são produzidas; são exogenamente determinadas.

5 Timmis (2003), por exemplo, faz um estudo da relação entre o clima das regiões brasileiras e o crescimento das epidemias no Brasil.
} 
dos e, finalizando, são tecidas as considerações finais.

\section{Modelo de escolha locacional}

\section{Modelo empírico}

De forma resumida, o modelo de escoIha locacional de Roback $(1980,1982)$ parte da suposição de que a função de utilidade do trabalhador depende, além das oportunidades econômicas ofertadas pela região onde o trabalhador mora, das dotações das amenidades da região. No modelo, a decisão locacional dos trabalhadores é influenciada pelo tradeoff entre as oportunidades econômicas ofertadas pelas regiões, traduzidas como o aumento de salário e redução no preço do aluguel, ${ }^{6}$ e a qualidade de vida das regiões, ou, seja, a dotação das amenidades das regiões. Em decorrência das hipóteses de equilíbrio do modelo - no equilíbrio de mercado os trabalhadores não têm ganhos de bem-estar migrando -, as regiões com maior dotação de amenidades tendem a ofertar menores salários e maior custo de habitação, de forma a igualar a utilidade entre as regiões. Já as localidades com baixos níveis de amenidades precisam oferecer boas oportunidades econômicas para atrair os trabalhadores e, assim, compensá-los por um menor consumo das amenidades.

Roback (1982), portanto, a partir da contribuição marginal das amenidades para a formação dos salários e aluguéis em cada região, recupera a informação do valor monetário que as pessoas atribuem ao consumo das amenidades. Obtém-se este valor regredindo o salário dos indivíduos que moram nas $j s$ localidades em função de atributos locais, que se quer valorar, controlando pelas características dos trabalhadores e de sua ocupação, na forma:

$w_{i j}=\beta_{0}+X_{i} \beta_{1}+Z_{j} \beta_{2}+u_{i j}$

onde: $w_{i j}$ corresponde ao salário que o indivíduo " $i$ " recebe na localidade " $j$ "; $X_{i}$ é um vetor das características individuais dos trabalhadores e da ocupação dos trabalha- dores, $Z_{j}$ refere-se ao vetor dos atributos locais; e $u_{i j}$ é o erro estocástico.

De forma semelhante, o preço do aluguel é regredido em função das amenidades locais, controlando pelas diferenças na qualidade do imóvel, como:

$r_{i j}=\theta_{0}+Q_{i} \theta_{1}+Z_{j} \theta_{2}+v_{i j}$

onde: $r_{i j}$ é o aluguel pago pelo indivíduo " $i$ " na localidade " $j$ "; $Q_{i}$ refere-se ao o vetor das características estruturais do imóvel; $Z_{j}$ corresponde ao vetor dos atributos locais; e $v_{j}$ é o erro estocástico.

A partir dos coeficientes dos atributos locais, de $d w / d z$ e de $d r / d z$, é calculada a função de preço implícito dado por:

$f_{a}=\frac{V a}{V w}=h \frac{d p}{d a}-\frac{d w}{d a}$

onde: " $h$ " representa a quantidade de terra consumida pelo trabalhador, comumente normalizada para $1 ; d p / d a$ é o diferencial do preço da terra de equilíbrio e $d w / d a$ corresponde ao diferencial salarial de equilíbrio. A função $f_{a}$ é denominada de função de preço implícito, a qual mensura o valor que as pessoas estão dispostas a pagar (ou que devem ser compensadas) por cada atributo local. Em outras palavras, a função de preço implícito quantifica o peso que cada atributo tem para a função de bem-estar dos trabalhadores.

Assim, com base na função de preço implícito, Roback (1982) propõe uma medida para mensurar a qualidade de vida (IQV) nas localidades, resultado do somatório entre a multiplicação do preço implícito de cada amenidade $(f a)$ pelo nível da amenidade na localidade " $j "$ ":

$I Q V_{j}=\sum_{k} f_{a k} a_{k j}$

O IQV é a soma da dotação dos " $k$ " atributos locais da localidade " $j$ ", ponderados pelas respectivas funções de preço implícito $(f)$, a qual mensura as preferências dos trabalhadores pelos atributos locais. Assim, quanto maior o IQV da localidade " $j$ ", maior é a qualidade das amenidades de " $j$ " em relação às demais $j s$ localidades consideradas na análise.

6 o preço do aluguel do imóvel é utilizado como proxy do custo da habitação no artigo, na impossibilidade de mensurá-lo. 


\section{Evidências empíricas}

Pode-se considerar que o modelo proposto por Roback (1982) - com a incorporação das empresas no modelo dos diferenciais compensados de Rosen (1979) - representa pioneiramente uma tentativa de construir um indicador de "qualidade" das amenidades, com embasamento teórico no comportamento em ambos os mercados: dos consumidores e das empresas.

A partir das contribuições pioneiras de Rosen (1979) e Roback (1982) para a construção de um índice de qualidade de vida, Blomquist et al. (1988) e Gyourko e Tracy (1991) flexibilizam algumas das hipóteses do modelo básico de Roback (1982). Blomquist et al. (1988) fazem variar as amenidades dentro de uma área urbana, assumindo que as economias de aglomeração podem influenciar a função de produção da empresa. Gyourko e Tracy (1991), por sua vez, incorporam no modelo os atributos fiscais que caracterizam cada região, respaldando-se na hipótese de que há atributos locais, como os serviços de segurança e educação, que os indivíduos pagam por meio de tributos e, portanto, segundo os autores, esses custos devem ser incluídos nas despesas das famílias.

Contudo, a despeito de essas extensões impostas ao modelo básico de Roback (1982) proporcionarem modelos teóricos mais realísticos, pode-se dizer que o modelo proposto por Blomquist et al. (1988) não traz contribuições relevantes para o cálculo do índice de qualidade de vida de Roback (1982), uma vez que o índice é derivado da condição de equilíbrio de mercado imposta aos trabalhadores. Já a respeito do que é sugerido por Gyourko e Tracy (1991), com a incorporação dos atributos fiscais na restrição orçamentária dos trabalhadores no modelo de Roback (1982), é preciso reconhecer que, se os dados dos preços dos serviços públicos não forem disponíveis para os pesquisadores, a implementação empírica com as extensões propostas por Gyourko e Tracy torna-se inviável. Além disso, as sugestões de Gyourko e Tracy (1991) são aplicáveis apenas quando há diferenças no sistema tributário entre as regiões em análise. ${ }^{7}$

Por outro lado, contrapondo a abordagem hedônica, alguns pesquisadores questionam se a hipótese de equilíbrio de mercado imposta pelo modelo dos diferenciais compensatórios de Roback (1982) - no equilíbrio de mercado, os consumidores não têm ganhos de bem-estar migrando da localidade que residem para outra qualquer - é sustentada na realidade (EVANS, 1990; GREENWOOD et. al, 1991; HARRIGAN; MCGREGOR, 1993).

A principal argumentação a favor dos que acreditam na persistência do desequilíbrio de mercado está relacionada com a não verificação da hipótese, que está por trás do modelo de Roback (1982), de que os mercados de trabalho e habitação são eficientes (EVANS, 1990; GREENWOOD et. al., 1991). Para Evans (1990) e Greenwood et. al. (1991), se não houver ajustamento instantâneo dos preços a um choque exógeno nos mercados, as análises com base no modelo de equilíbrio espacial de Roback (1982) podem levar a conclusões erradas do verdadeiro valor que os trabalhadores atribuem ao consumo das amenidades. Graves e Muesser (1993) contra-argumentam e defendem a ideia de que algumas suposições impostas a modelos originalmente desenvolvidos de demanda, inicialmente, são necessárias para tornar os modelos aplicáveis. Além disso, estes autores colocam que Roback (1982) não descarta a possibilidade da tendência dos mercados ao desequilíbrio, quando inclui o crescimento populacional no modelo empírico, nas equações de salários e aluguéis.

Em geral, os pesquisadores que investigam se o mercado de trabalho está em equilíbrio associam os contínuos movimentos migratórios como um fenômeno de desequilíbrio (EVANS, 1990; GREENWOOD et. al., 1991). Greenwood et al. (1991), por exemplo, verificam a suposição de

\footnotetext{
7 Gyourko et al. (1997) fazem uma análise crítica de estudos empíricos aplicados para a valoração de amenidades desenvolvidos a partir do modelo de Roback (1982).
} 
equilíbrio igualando a taxa de migração líquida - função do valor presente do salário potencialmente ganho e das amenidades locais - a zero, assumindo, assim, que, se a renda estimada de equilíbrio, obtida para cada região, diferir da renda observada, os mercados estariam em desequilíbrio. Por outro lado, Berger et al. (2003) e Gyourko et al. (1997) contra-argumentam colocando que a existência de migração não necessariamente implica um fenômeno de desequilíbrio. Como exemplo, os autores citam os movimentos migratórios advindos do efeito ciclo de vida, os quais podem ser fenômenos de equilíbrio. ${ }^{8}$ Graves e Muesses (1993), embora reconheçam que os motivos que levam à persistência da migração líquida devam ser examinados, discordam quando a persistência do desequilíbrio de mercado é associada à existência de migração, a partir de um modelo derivado para um ponto no tempo.

Quanto aos estudos empíricos que objetivam valorar as amenidades locais a partir da abordagem hedônica, aplicados principalmente para os Estados Unidos, é possível identificar pelo menos dois principais objetivos de pesquisa. Aqueles que buscam investigar a influência das características da vizinhança - tais como proximidade de boas escolas, hospitais, qualidade ambiental, entre outras amenidades - no preço dos imóveis, para uma determinada unidade geográfica de análise (SONG; KNAAP, 2003; BRASINGTON; HETE, 2003; DOWNES; ZABEL, 2002), objetivam analisar o mercado de habitação em função das preferências dos consumidores pela vizinhança, com vista a estimar o valor que os indivíduos estão dispostos a pagar - embutido no preço do imóvel - por morar em localidades que tenham "boa" vizinhança.

Com outro objetivo de análise, têm-se os estudos realizados para um grupo de unidades geográficas, como, por exemplo, as regiões metropolitanas, que visam, de modo geral, obter evidências da qualidade das amenidades das regiões em estudo, a partir da escolha locacional dos trabalhadores (BLOMQUIST et al., 1988; GYOURKO et al., 1991; STAURT et al., 1996; BERGER et al., 2003).

Para o Brasil, são poucos os estudos empíricos que objetivam valorar as amenidades com um enfoque regional. Ainda mais escassos são os que unem os dois setores, o de trabalho e o habitacional, para inferir sobre o valor que as pessoas estão propensas a pagar pelas amenidades. Em parte, pode-se associar esta relativa escassez de trabalhos empíricos realizados para o Brasil à limitação dos dados que estão disponíveis para o país, pois não existe um banco de dados integrado para as unidades geográficas brasileiras, com informações sobre os imóveis. Além disso, são limitados ou inexistentes os dados de amenidades naturais para as unidades geográficas do Brasil, como, por exemplo, indicadores da qualidade ambiental, com uma desagregação para as cidades ou regiões metropolitanas.

Contudo, cabe fazer referência a três trabalhos. Herman e Haddad (2005) realizam um exame localizado para a Região Metropolitana de São Paulo, com o objetivo de examinar a influência das amenidades urbanas sobre o preço dos imóveis. O método de estimação adotado é o hedônico (ROSEN, 1974) e os autores utilizaram a construção de fatores para minimizar o efeito da multicolinearidade presente nos dados. O exame é realizado a partir de uma amostra de 497 imóveis da base de dados da Pesquisa Orçamento Familiar (POF) de 1999, da Fipe, georreferenciado pelo endereço de cada domicílio. Os autores exploraram dados de amenidades tanto naturais quanto sociais: indicadores de criminalidade na área ao redor dos imóveis; qualidade do meio ambiente, representada pelo coeficiente arbóreo; variáveis de acessibilidade do imóvel aos principais centros (distância ao centro histórico de São Paulo, ao centro novo, e outra variável com a distância mínima entre

\footnotetext{
${ }^{8}$ Há na literatura econômica uma discussão, embora sem um consenso, em torno da hipótese de equilíbrio de mercado do modelo de Roback (1982) (LINNEMAN; GRAVES, 1983; EVANS, 1990; HARRIGAN; MCGREGOR, 1993; GRAVES; MUESER, 1993; SCHACHTER; ALTHAUS, 1989).
} 
os dois centros); e acesso ao transporte público (as estações de trem). Herman e Haddad (2005) encontraram evidências de que os imóveis próximos às estações de trem e de áreas arborizadas tendem a ser mais valorizados, enquanto a criminalidade tem efeito contrário no preço do imóvel. Além destes resultados, a partir do modelo estimado com a inclusão dos fatores, os autores obtiveram indicações de que, além das amenidades citadas anteriormente, os imóveis com um melhor acesso aos serviços de modo geral são mais valorizados. Por outro lado, a partir de testes de dependência espacial aplicados aos modelos, a hipótese de dependência espacial entre os preços dos imóveis foi rejeitada, resultado este não esperado.

Com outro enfoque de análise - o mercado de trabalho -, Silveira Neto e Azzoni (2004) estimam uma equação tipicamente minceriana dos salários, com o objetivo de examinar a influência de algumas amenidades, sociais e naturais, para a persistência dos diferencias de renda entre os residentes nas aéreas urbanas dos Estados brasileiros. A partir dos diferenciais de renda observados entre as unidades da federação, os autores inferem sobre as diferenças na qualidade das amenidades entre as áreas urbanas das unidades geográficas de análise. $O$ estudo, realizado com base na PNAD de 2002, incorpora, no exame empírico, dummies para as grandes regiões, a razão entre a população residente na costa e a população total, temperatura média do mês de julho, média da precipitação anual, altitude, latitude e amenidades sociais, representadas por três indicadores: taxa de mortes violentas; índice de Gini; e participação dos trabalhadores no setor de alojamento e alimentação em relação ao pessoal ocupado total. Os resultados encontados pelos autores indicaram que as Regiões Sul e Nordeste estão mais bem servidas pelas amenidades incorporadas no exame quando comparadas com a Região Sudeste. Mas os resultados sugerem que a qualidade das amenidades do Sudeste é melhor do que as do Norte e Centro-Oeste.

Os autores também encontraram evidência da importância de se considerarem as diferenças no custo de vida para explicar diferenças regionais nos salários entre os trabalhadores residentes na área urbana das unidades da federação. E, por meio de regressões quantílicas, Silveira Neto e Azzoni (2004) obtiveram evidências de que as disparidades de renda entre as Regiões Nordeste e Sudeste tendem a ser mais significativas para os quantis de renda menores, tendendo a diminuir quando são considerados os trabalhadores de classes salariais mais elevadas.

Unindo os dois mercados, o de trabalho e o de habitação, conforme proposto por Roback (1980,1982), e buscando minimizar os problemas econométricos gerados pela inclusão de amenidades endógenas nas equações hedônicas de salários e aluguéis, Monte (2004) estima a propensão a pagar pelas amenidades de clima: temperatura média anual; variação da temperatura anual; volume total da precipitação anual; umidade relativa do ar; horas de sol; além da distância para a praia mais próxima. $\mathrm{O}$ autor utilizou a Pesquisa de Orçamento familiar (POF), como fonte das características dos imóveis e dos trabalhadores, e os dados de clima estão reportados no Anuário Estatístico do Brasil de 1987, do IBGE. Os resultados encontrados indicam que o aumento da temperatura média anual e da variação impactam positivamente a função de utilidades dos trabalhadores. Os demais resultados sugerem que os trabalhadores preferem morar nas regiões metropolitanas menos umidas, em relação às RMs que foram incorporadas no exame, nas RMs com menos horas de sol, e próximas ao mar.

\section{Implementação empírica}

\section{Base de dados}

A base de dados utilizada na pesquisa foi construída a partir de três fontes principais: a Pesquisa Nacional por Amostra e Domicílios (PNAD), do Instituto Brasileiro de Geografia e Estatística (IBGE), em que foram extraídos os dados das características e da ocupação dos trabalhadores e dos atributos dos imóveis; o Instituto Nacional de Meteorologia, para as informações climáticas do período de 1990 a 2006; e o Centro de 
Previsão de Tempo e Estudos Climáticos (CPTEC), para os dados sobre o nível de poluição.

A unidade geográfica de analise corresponde às Regiões Metropolitanas de Belém, Fortaleza, Recife, Salvador, Belo Horizonte, Rio Janeiro, São Paulo, Curitiba e Porto Alegre. O Mapa 1 apresenta a localização geográfica das RMs.

A amostra definida para o exame empírico é composta por todos os chefes da família (declarados na PNAD como pessoa de referência da família), que trabalham em atividades não agrícolas, com mais de 15 anos, com algum ganho positivo na semana de referência em que foi entrevistado e que mora em imóvel alugado. A amostra final é composta por 5.636 pessoas, a qual, expandida pelo peso da PNAD, representa $4 \%$ da população total das regiões metropolitanas consideradas na pesquisa.

A variável dependente da equação dos salários é a renda mensal derivada do trabalho da pessoa de referência da família,

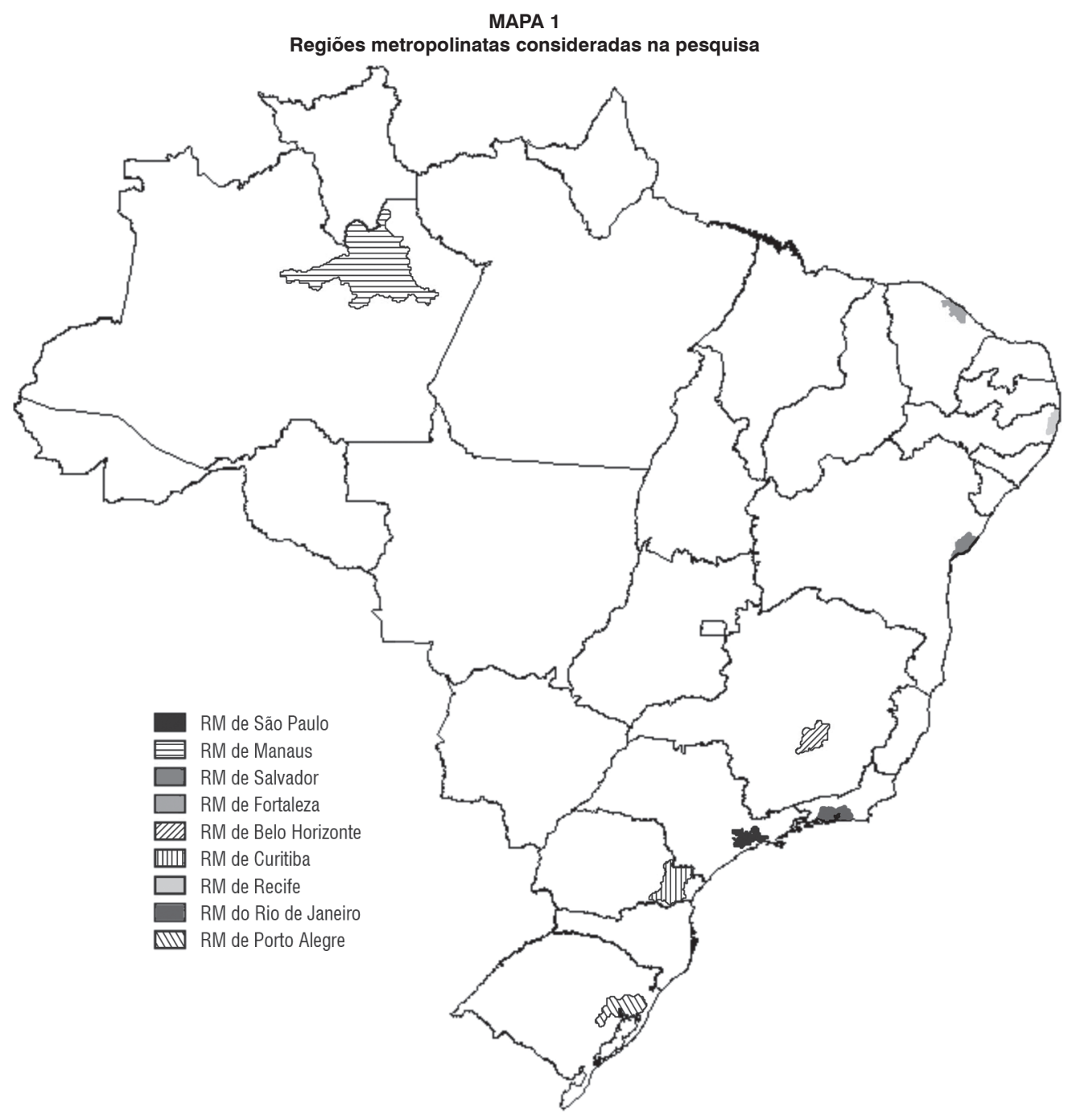

Fonte: Elaboraçao dos autores. 
e a variável dependente da equação dos aluguéis corresponde ao preço do aluguel pago mensalmente.

Assim, seguindo a literatura padrão sobre os diferenciais compensatórios de renda (ROBACK, 1982), na equação dos salários foi incluído, além de um vetor de variáveis controles das características dos trabalhadores e da ocupação do trabalho dos trabalhadores, um vetor de atributos locais das regiões metropolitanas, os quais serão especificados a seguir. De forma semelhante, na equação dos aluguéis, incluiu-se, além de um vetor com informações sobre as características estruturais do imóvel, o mesmo vetor de variáveis dos atributos locais que foi considerado na equação dos salários.

Entre os dados das amenidades naturais incorporados no exame empírico, estão indicadores do nível da precipitação $(\mathrm{mm})$, da temperatura média mensal $(\stackrel{\circ}{ } \mathrm{C})$ e da umidade relativa do ar (\%), observados no período de 1990 a 2006. ${ }^{9}$

Foram incluídas, na análise, as médias mensais das temperaturas de janeiro e julho, respectivamente, o mês mais quente e o mais frio do ano para a maior parte das regiões metropolitanas. Com relação aos meses escolhidos, espera-se que aqueles com temperaturas extremas tenham uma maior influência para o bem-estar dos indivíduos do que aqueles com temperaturas mais amenas.

Com o propósito de explorar um indicador "médio" e outro que captasse a variação da precipitação, a média das observações da precipitação anual e a média das observações da precipitação do mês de setembro foram as variáveis consideradas na análise. Outra variável climática incorporada no exame empírico corresponde à média dos registros da umidade relativa do ar durante o período em análise. Esse atributo climático influencia na sensação térmica, ${ }^{10}$ juntamente com a temperatura, a velocidade e a direção dos ventos e, por isso, é sempre utilizado em estudos desta natureza (CRAGG; KAHN, 1997; TIMMIS, 1999).

Também foram considerados, no exame empírico, outros dois importantes atributos locais: uma variável de proximidade para a costa, que compreende a distância entre a capital e a praia mais próxima $(\mathrm{km})$; e uma variável proxy do nível da poluição do ar - o material particulado decorrente de queimadas calculado com base em Freitas et al. (2005), ${ }^{11}$ que constitui um dos componentes da poluição do ar.

Em paralelo, um modelo foi estimado incluindo, além das amenidades naturais descritas anteriormente, a latitude, variável significantemente correlacionada com o IDH. ${ }^{12} \mathrm{Um}$ terceiro modelo também foi estimado, incorporando a densidade demográfica, a qual pode ser considerada uma proxy das amenidades sociais ou das amenidade negativas geradas pelo congestionamento dos bens públicos. Menezes Filho et al. (2006) encontram evidências de que a latitude é um bom instrumento para a qualidade das instituições atuais, utilizando-a para examinar a relação entre a qualidade das instituições atuais e o Produto Interno Bruto per capita das capitais brasileiras. ${ }^{13} \mathrm{~A}$ Justificativa para esta relação está na tendência de os Estados do Norte e Nordeste serem menos desenvolvidos do que os do Sudeste e Sul, o que deve ter uma relação com a localização geográfica (latitude média) dos Estados e com a forma como foram colonizados, o que repercuti na qualidade das suas instituições atuais.

\footnotetext{
${ }^{9}$ Esse período foi escolhido porque é provável que o indivíduo, ao fazer avaliações sobre o clima de uma região, tome como referência os anos recentes. Além disso, são utilizadas as médias do período de forma a suavizar os dados para os anos atípicos, com elevadas ou baixas temperaturas, que poderiam distorcer a média histórica. Porém, admite-se que o indicador baseado em médias apenas informa uma tendência média, não captando medidas atípicas.

10 Para referências, consultar Frota e Schiffer (2007) e Lowry (1977).

${ }_{11}$ Além de o material particulado decorrente de queimadas - dados esses que foram concedidos pela equipe do CPTEC - apresentar uma baixa correlação com a renda per capita das RMs, um índice de correlação 4\%, segundo a Pesquisa de Meio Ambiente Municipal do IBGE realizada em 2002, entre as causas apontadas da poluição do ar nos municípios brasileiros, a poluição decorrente das queimadas apresentou a maior participação no total dos municípios.

12 Contudo, é importante registrar que a latitude e o IDH apresentaram um índice de correlação significativamente elevado, um coeficiente negativo de $84 \%$.

${ }_{13}$ As estatísticas descritivas dos dados utilizados na pesquisa encontram-se no Anexo.
} 
Quanto aos coeficientes estimados dos atributos locais, de acordo com a abordagem hedônica, deve-se esperar que seja negativo o diferencial do salário com relação ao atributo local e positivo o diferencial do preço do aluguel, se o aumento marginal do atributo impactar positivamente a função de utilidades dos trabalhadores. Caso contrário, se o incremento marginal do atributo influenciar negativamente a função de utilidade dos trabalhadores, o sinal do coeficiente estimado a partir da equação de salários deverá ser positivo, e o sinal do coeficiente obtido pela estimação da equação de aluguéis, negativo.

\section{Equação reduzida dos salários e aluguéis}

Três equações na forma reduzida do salário são estimadas. A primeira inclui apenas atributos climáticos, geográficos e da poluição do ar (modelo 1). Além desta, mais duas equações dos salários são estimadas, considerando, além dos atributos do modelo 1: a latitude (modelo 2); e a densidade demográfica (modelo 3 ). Os modelos estimados em forma de equação podem ser representados como:

$$
\begin{aligned}
& \text { 1: } w_{i j}=\beta_{0}+\beta_{1} \text { carc_ind }+\beta_{2} \text { carc_ocup }_{j}+\beta_{3_{j}} \text { clima }_{j}+\mu_{i j} \text { (5) } \\
& 2: w_{i j}=\beta_{0}+\beta_{1} \text { carcind }+\beta_{2} \text { carcosup }_{j}+ \\
& \quad+\beta_{3} \text { clima }_{j}+\beta_{4} \text { lat }+\mu_{i j} \\
& \text { 3: } w_{i j}=\beta_{0}+\beta_{1} \text { carc_ind }+\beta_{2} \text { carc_ocup }_{j}+ \\
& \quad+\beta_{3} \text { clima }_{j}+\beta_{4} \text { den }+\mu_{i j}
\end{aligned}
$$

A variável dependente é a da renda do trabalho do indivíduo "i" que mora na localidade " $j$ ". A equação dos salários é composta por um conjunto de variáveis controles das características socioeconômicas do trabalhador (carc_ind), do setor de atividade em que o indivíduo está empregado e da categoria da ocupação do trabalhador (carc_ocup); e dos atributos locais (clima). Além destas, têm-se as variáveis latitude $(L A T)$ (modelo 2) e densidade demográfica $(D E N)$ (modelo 3). E $\mu_{i}$ é o termo de erro dos modelos.

Desta forma, no vetor carc_ind, incluíram-se: uma variável dummy para o sexo do trabalhador (sexo), tomando o valor 1 se for do sexo feminino (0 caso contrário); a idade (idade); a idade ao quadrado (idade ${ }^{2}$ ); e uma variável dummy para a raça do indivíduo ( $r a c ̧ a), 1$ se é branca ( 0 outro caso). Também foram incorporados um vetor de variáveis dummies para os anos de estudos - se o trabalhador tem de 1 a 3 anos de estudos (est $1 a 3)$, de 4 a 7 dos (est $4 a 7)$, de 8 a 10 (est $8 a 10)$, de 11 a 14 (est11a14) e 15 anos ou mais de estudo (est15mais), em relação aos trabalhadores com menos de um ano de estudo (categoria omitida) - e um vetor de dummies para o tipo de família: casal sem filhos (familia1); casal com todos os filhos menores de 14 anos (família2); casal com filhos menores de 14 anos e de 14 anos ou mais (familia3); mãe com todos os filhos menores de 14 anos (familia4); mãe com todos os filhos de 14 anos ou mais (familia5); mãe com filhos menores de 14 anos e de 14 anos ou mais (família6) e outros tipos de família; sendo que a categoria de comprarão é casal com todos os filhos de 14 anos ou mais.

O vetor carc ocup de variáveis inclui dummies para a posição da ocupação do trabalhador: se o trabalhador tem carteira assinada (posiçaol); se é funcionário público estatutário ou militar (posição2); se é autônomo (posiçao3); e se é empregador (posiçao4), em relação aos empregados sem carteira assinada e aqueles sem declaração de carteira (categoria de comparação). Também são incluídos dummies para o setor de atividade do trabalho do indivíduo: indústria da transformação e outras atividades industriais (setor1); construção (setor2); comércio (setor3); alojamento e alimentação (setor4); transporte, armazenagem e comunicação (setor5); educação, saúde e serviços sociais (setor6); serviços domésticos (setor7); outras atividades (setor 8), sendo que o setor referência de comparação é o de administração pública.

No vetor clima incorporaram-se a média mensal das observações da precipitação $(\mathrm{mm})$ de setembro (RSEP), as médias mensais das temperaturas $\left({ }^{\circ} \mathrm{C}\right)$ de janeiro $(T J A N)$, mês mais quente do ano, e de juIho (TJUL), mês mais frio do ano; a média da umidade relativa do ar (\%) (UANUAL), a média das observações da precipitação anual (RANUAL) e a distância para a praia mais próxima $(\mathrm{km})(D I S T M A R)$. Além destas 
variáveis, foi incluída, no vetor clima, uma variável proxy do nível de poluição da região metropolitana: o material particulado decorrente de queimadas $(P M)$.

Da mesma forma, os três modelos são estimados para a equação dos aluguéis. As formas reduzidas das equações são:

$$
\begin{aligned}
1: r_{i j}=\beta_{0}+\beta_{1} * m o r / c o m+\beta_{2} * \text { car } i m o v+ \\
\quad+\beta_{3} * \text { clima }+v_{i j} \\
2: r_{i j}=\beta_{0}+\beta_{1} * m o r / c o m+\beta_{2} * \text { car imov }+ \\
\quad+\beta_{3} * \text { clima }+\beta_{4} l a t+v_{i j} \\
3: r_{i j}=\beta_{0}+\beta_{1} * m o r / c o m+\beta_{2} * \text { car imov }+ \\
\quad+\beta_{3} * \text { clima }+\beta_{4} d e n+v_{i j}
\end{aligned}
$$

onde a variável dependente é o preço do aluguel mensal, $r_{i j}$. Nestas equações, o vetor "mor/com" é composto por uma variável que busca captar a densidade do imóvel, número de moradores dividido pelo número de cômodos (morcom), o número de cômodos do imóvel (ncomo), o número de cômodos do imóvel que servem de dormitório (ndorm), e o número de banheiros do imóvel (nbanheiro). O vetor "car imov" inclui uma variável dummy, napart, igual a 1 se o imóvel é uma casa ou cômodo (0 caso contrário); e duas variáveis dummies para o acesso a serviços básicos de saneamento: se o imóvel tem acesso à coleta direta do lixo (lixo); e se o imóvel está ligado à rede coletora de esgoto ou pluvial (esgoto). O vetor clima é o mesmo considerado nas equações dos salários. $\mathrm{O}$ termo de erro dos modelos é $v_{i j}$.

\section{Analise dos resultados}

\section{Equações dos diferenciais salariais e das} equações dos aluguéis

As Tabelas 1 e 2 apresentam os resultados dos três modelos estimados a partir da equação hedônica dos salários e da equação hedônica dos aluguéis, respectivamen- te. A variável dependente, na equação dos salários, é o salário real mensal e, na equação dos aluguéis, é o preço real do aluguel pago mensalmente. Como o objetivo principal da pesquisa é estimar a função de preço implícito dos atributos locais considerados nos modelos empíricos definidos na seção anterior, sendo, portanto, as características dos trabalhadores e dos imóveis apenas "variáveis controles", nas Tabelas 1 e 2 são omitidos os coeficientes estimados dessas últimas variáveis. Ou seja, aqui não são analisados os diferenciais dos salários ${ }^{14} \mathrm{em}$ função das características individuais dos trabalhadores e da ocupação do trabalho, como meio de explicação da persistência dos diferencias da remuneração do trabalho entre as regiões metropolitanas, mas sim os diferenciais dos salários e aluguéis com respeito aos atributos locais incorporados nos modelos. Contudo, vale salientar que as referidas variáveis controles incorporadas nos modelos apresentaram sinais condizentes com as evidências observadas para as regiões metropolitanas brasileiras.

Quanto aos resultados dos modelos estimados da equação dos salários, todos os coeficientes dos atributos locais mostraram-se significantes a 5\% e, também, são conjuntamente significantes. Contudo, cabe ressaltar que os resultados obtidos pela estimação dos modelos 2 e 3 são utilizados apenas como parâmetros de comparação com o modelo 1, já que a variável DENSIDADE é endogenamente determinada pelo modelo, pois as regiões que oferecem melhores oportunidades econômicas tendem a atuar como uma força de atração dos trabalhadores. Além disso, o segundo modelo estimado, incluindo a variável LATITUDE, também pode apresentar esse viés, já que tal variável está significativamente correlacionada com o Índice de Desenvolvimento Humano (IDH).

Assim, a análise é realizada enfatizando, principalmente, os resultados obtidos pela estimação do modelo 1.

\footnotetext{
14 O foco de análise é em torno dos coeficientes dos atributos locais e não das características individuais dos trabalhadores, como, por exemplo, os estudos que objetivam examinar os diferenciais salariais em função da discriminação no mercado de trabalho.
} 
A respeito da interpretação dos coeficientes estimados dos atributos locais, de acordo com a abordagem hedônica, deve-se esperar que o diferencial do salário com relação ao atributo local seja negativo, se o atributo impacta positivamente a função de utilidade dos trabalhadores, indicando que o trabalhador está disposto a receber um menor salário na localidade que Ihe ofereça uma maior dotação de tal amenidade. Caso contrário, se o incremento marginal do atributo local impactar negativamente a função de utilidade dos trabalhadores, o sinal do coeficiente estimado deverá ser positivo, pois, nesse caso, o trabalhador deve ser compensado com um maior salário para residir em uma localidade com uma menor dotação da amenidade.

Tendo, assim, como referência para a análise os resultados obtidos pela estimação do modelo 1 , nota-se que a variável material particulado $(P M)$ apresentou sinal negativo, o que contradiz as expectativas de que a qualidade do ar é uma amenidade para os trabalhadores. Contudo, é possível que essa variável seja correlacionada com outras variáveis econômicas e, portanto, pode estar captando a influência dessas variáveis, como, por exemplo, da capacidade produtiva da região na formação dos salários pagos.

Por outro lado, o sinal positivo da variável distância para o mar (DISTMAR) corrobora as expectativas de que os trabalhadores preferem morar em regiões próximas ao mar e, por isso, devem ser compensados com um maior salário para morar mais distantes do litoral.

Ainda de acordo com resultados do modelo 1 , há indicações de que os trabaIhadores devem ser compensados com um maior salário para morar nas regiões metropolitanas com maiores índices médios de precipitação $(R A N U A L)$. Mas, o sinal negativo do coeficiente da precipitação média do mês de setembro (RSET) indica que esse atributo é uma amenidade para os trabalhadores, impactando negativamente no seu salário.

A respeito da variável umidade relativa do ar (UANUAL), os resultados sugerem que um incremento marginal nessa variável impacta negativamente nos salários dos trabalhadores, sugerindo, conforme preconiza

TABELA 1

Resultados dos modelos de regressão estimados a partir das equações estimadas dos salários Regióes metropolitanas do Brasil (1) - 2006

\begin{tabular}{|c|c|c|c|c|c|c|}
\hline \multirow[b]{2}{*}{ Variáveis } & \multicolumn{2}{|c|}{ Modelo 1} & \multicolumn{2}{|c|}{ Modelo 2} & \multicolumn{2}{|c|}{ Modelo 3} \\
\hline & $\beta$ & $\begin{array}{c}\text { Erro } \\
\text { padrão }\end{array}$ & $\beta$ & $\begin{array}{c}\text { Erro } \\
\text { padrão }\end{array}$ & $\beta$ & Erro padrão \\
\hline PM2_5 & $-8,09$ & 0,898 & $-32,88$ & 1,077 & $-15,55$ & 0,914 \\
\hline DISTMAR & 0,10 & 0,0127 & 0,42 & 0,015 & 1,53 & 0,037 \\
\hline RANUAL & 16,87 & 2,538 & 60,23 & 2,692 & $-46,76$ & 3,043 \\
\hline UANUAL & $-12,97$ & 0,494 & 16,07 & 0,90 & 34,49 & 1,296 \\
\hline$R S E T$ & 20,10 & 2,143 & $-60,59$ & 2,85 & $-21,98$ & 2,340 \\
\hline TJAN & $-13,09$ & 1,297 & $-47,01$ & 1,57 & 15,81 & 1,44 \\
\hline TJUL & 4,17 & 0,906 & 47,59 & 1,43 & $-6,71$ & 0,928 \\
\hline LATITUDE & - & - & $-34,79$ & 0,847 & - & - \\
\hline DENSIDADE & - & - & - & - & 0,14 & 0,003 \\
\hline Constante & 594,19 & 47,13 & $-2151,70$ & 82,81 & $-3377,34$ & 108,693 \\
\hline R2 Ajustado & \multicolumn{2}{|c|}{0,363} & \multicolumn{2}{|c|}{0,363} & \multicolumn{2}{|r|}{0,363} \\
\hline N. Observações & \multicolumn{2}{|c|}{2.453 .947} & \multicolumn{2}{|c|}{2.453 .947} & \multicolumn{2}{|c|}{2.453 .947} \\
\hline
\end{tabular}

Fonte: IBGE. Pesquisa Nacional por Amostra e Domicílios (PNAD); Instituto Nacional de Meteorologia (INMTE); Centro de Previsão de Tempo e Estudos Climáticos (CPTEC). Elaboração dos autores.

(1) Referem-se às RMs de Belém, Fortaleza, Recife, Salvador, Belo Horizonte, Rio de Janeiro, São Paulo, Curitiba e Porto Alegre. Nota: Todos os coeficientes estimados são significantes a menos $5 \%$. Erro padrão ajustado pelo critério de White. 
a abordagem hedônica, que tal variável é uma amenidade para os trabalhadores.

Quanto à temperatura média do mês de janeiro $(T J A N)$, o diferencial do salário com relação à variável apresentou o sinal negativo, sugerindo que tal variável é uma amenidade para os trabalhadores. Mas, de acordo com os resultado do modelo 1 , a temperatura média de julho (TJUL) atua como uma "amenidade negativa" para os trabalhadores, já que eles devem ser compensados com um maior salário para morar nas regiões metropolitanas mais quentes.

Comparando os resultados do modelo $1 \mathrm{com}$ aqueles obtidos a partir dos modelos 2 e 3, nota-se que a inclusão das variáveis LATITUDE, no segundo modelo, e DENSIDADE, no terceiro, alterou o sinal dos coeficientes de algumas variáveis.

O coeficiente da variável LATITUDE, referente ao modelo 2 , apresentou o sinal negativo, indicando que as pessoas devem ser compensadas com um maior salário por morar em regiões com menores latitudes. $A$ variável LATITUDE, correlacionada positivamente com o IDH, pode captar a influência de outras variáveis, além dos fatores climáticos, nos diferenciais salariais.

Por fim, o coeficiente positivo da variável densidade demográfica (DENSIDADE), do modelo 3 , sugere que esse atributo é uma "amenidade negativa" para os trabalhadores, uma vez que eles devem ser compensados com um maior salário para morar em regiões densamente povoadas.

Analisando agora os resultados obtidos pela estimação das equações dos aluguéis (Tabela 2) , observa-se que os atributos dos imóveis incorporados no exame empírico explicam em torno de $56 \%$ da formação dos preços dos aluguéis nas regiões metropolitanas. Além disso, os coeficientes das variáveis incluídas nos modelos empíricos são estatisticamente significantes a $5 \%$ e, também, são conjuntamente significantes.

A respeito da interpretação dos sinais dos coeficientes estimados, a partir das equações dos aluguéis, segundo preconiza a abordagem hedônica, se a variável apresentar o sinal positivo, significa que o atributo é uma amenidade para os trabaIhadores, os quais estão dispostos a pagar um maior preço do aluguel para morar nas regiões metropolitanas com uma maior dotação da amenidade. Por outro lado, se o atributo apresentar o coeficiente negativo, indica que um incremento marginal implicará perdas de bem-estar para os trabalhadores e, portanto, eles deverão ser compensados com um menor preço do aluguel para morar nas localidades menos dotadas do atributo.

Dessa forma, tomando como referência o modelo 1, os resultados da equação hedônica dos aluguéis sugerem que o aumento de um dos componentes da poluição do ar - o material particulado $(P M)$ - influencia positivamente no valor do aluguel, o que contraria as expectativas de que tal atributo é uma "amenidade negativa" para os trabaIhadores. Contudo, do mesmo modo que foi argumentado para a equação dos salários, é possível que a variável capte a influência de outras variáveis nos diferenciais dos aluguéis, como, por exemplo, o crescimento econômico da região, sendo que esse efeito pode superar as externalidades negativas geradas pela poluição do ar.

Quanto aos demais coeficientes estimados dos atributos locais, o sinal negativo do coeficiente da distância para o mar (DIST$M A R$ ) sugere que o aumento desta distância desvaloriza o preço do imóvel, resultado esse também encontrado por Monte (2004). Há ainda indicações, de acordo com o modelo 1 , de que um incremento na umidade relativa do ar (UANUAL) impacta negativamente o bem-estar dos trabalhadores.

Com respeito aos atributos de precipitação, os resultados sugerem que a precipitação média anual (RANUAL) representa uma amenidade para os trabalhadores, enquanto a precipitação média de setembro (RSET) constitui uma "amenidade negativa", sendo que a primeira atua valorizando o preço do aluguel do imóvel e a segunda desvalorizando.

Para os atributos de temperatura, o sinal positivo da temperatura média de janeiro (TJAN) sugere que o aumento da temperatura neste mês influencia positivamente a função de bem-estar dos trabalhadores, enquanto o incremento da temperatura média de julho (TJUL) atua negativamente. 
TABELA 2

Resultados dos modelos de regressão estimados a partir das equações hedônicas de aluguéis Regiões Metropolitanas do Brasil (1) - 2006

\begin{tabular}{|c|c|c|c|c|c|c|}
\hline \multirow{2}{*}{ Variáveis } & \multicolumn{2}{|c|}{ Modelo1 } & \multicolumn{2}{|c|}{ Modelo 2} & \multicolumn{2}{|c|}{ Modelo 3} \\
\hline & $\beta$ & Erro padrão & $\beta$ & Erro padrão & $\beta$ & $\begin{array}{l}\text { Erro pa- } \\
\text { drão }\end{array}$ \\
\hline$P M$ & 19,75 & 0,10 & 7,02 & 0,13 & 15,27 & 0,11 \\
\hline DISTMAR & $-0,21$ & 0,00 & $-0,07$ & 0,00 & 0,46 & 0,00 \\
\hline RANUAL & 57,16 & 0,30 & 74,67 & 0,31 & 23,69 & 0,36 \\
\hline UANUAL & $-5,99$ & 0,06 & 7,06 & 0,10 & 15,84 & 0,15 \\
\hline RSEP & $-6,02$ & 0,25 & $-40,97$ & 0,32 & $-22,58$ & 0,26 \\
\hline TJAN & 23,54 & 0,17 & 4,78 & 0,20 & 34,72 & 0,18 \\
\hline TJUL & $-13,32$ & 0,11 & 8,94 & 0,18 & $-16,94$ & 0,12 \\
\hline LATITUDE & - & - & $-16,58$ & 0,11 & - & - \\
\hline$D E N S I D A D E$ & - & - & - & - & 0,07 & 0,00 \\
\hline Constante & $-247,12$ & 5,46 & $-1464,13$ & 9,04 & $-2048,18$ & 12,76 \\
\hline R2 Ajustado & \multicolumn{2}{|c|}{0,559} & \multicolumn{2}{|c|}{0,563} & \multicolumn{2}{|c|}{0,563} \\
\hline N. Observações & \multicolumn{2}{|c|}{2.453 .947} & \multicolumn{2}{|c|}{2.453 .947} & \multicolumn{2}{|c|}{2.453 .947} \\
\hline
\end{tabular}

Fonte: IBGE. Pesquisa Nacional por Amostra e Domicílios (PNAD); Instituto Nacional de Meteorologia (INMTE); Centro de Previsão de Tempo e Estudos Climáticos (CPTEC). Elaboração dos autores.

(1) Referem-se às RMs de Belém, Fortaleza, Recife, Salvador, Belo Horizonte, Rio de Janeiro, São Paulo, Curitiba e Porto Alegre. Nota: Todos os coeficientes são estatisticamente significantes a 5\%. Erro padrão ajustado pelo critério de White.

Também foi evidenciado, pela estimação do modelo 2, que os trabalhadores preferem morar nas regiões metropolitanas com latitudes mais elevadas. A respeito do coeficiente da densidade demográfica (DENSIDADE), o sinal positivo do coeficiente da variável (modelo 3 ) sugere que um incremento marginal na densidade demográfica age valorizando o preço do aluguel do imóvel.

Estimação da propensão marginal a pagar pelas amenidades e construção do índice de qualidade de vida hedônico

Com base nos coeficientes obtidos a partir da estimação das equações dos salários e dos aluguéis, é derivada a função de preço implícito que os trabalhadores estão dispostos a pagar por cada atributo local " $z$ ", calculado pela diferença entre o coeficiente estimado do atributo local com base na equação hedônica dos aluguéis $\left(d r / d z=\beta_{z}^{r}\right)$ e do coeficiente estimado a partir da equação hedônica dos salários $\left(d w / d z=\beta_{z}^{w}\right)$ :

$f_{z}=\beta_{z}^{r}-\beta_{z}^{w}$

onde $\beta_{z}^{r}$ é o coeficiente do atributo " $z$ " obtido pela estimação da equação dos aluguéis, e $\beta^{w}{ }_{z}$ é o coeficiente do atributo " $z$ ", estimado a partir da equação dos salários.

Dessa forma, de acordo com a abordagem hedônica, se o atributo local " $z$ " representar uma amenidade para os trabalhadores, a função de preço implícita quantifica o quanto os trabalhadores estão dispostos a pagar por um incremento marginal no atributo. No caso contrário, se um incremento no atributo local impactar negativamente a função de utilidade dos trabalhadores, a função de preço implícito apresentará o sinal negativo.

A Tabela 3 informa sobre o preço implícito de cada atributo local incorporado no exame empírico, calculado com base na expressão (11), conforme sugerido por Roback (1982). Analisando, assim, as funções de preço implícito, referente ao modelo 1 , na ordem como estão dispostos na Tabela 3 , observa-se que o sinal positivo do preço implícito da poluição do ar $(P M)$ sugere que o incremento marginal da poluição do ar influencia positivamente a função de utilidade dos trabalhadores. Mais uma vez, pode-se intuir que essa variável deve estar captando a influência de outras variáveis que são correlacionadas com a mesma e, nesse caso, não estaria refletindo o verdadeiro 
TABELA 3

Função de preço implícito ou propensão marginal a pagar pelos atributos locais Regiões metropolitanas do Brasil (1) - 2006

\begin{tabular}{lccc}
\hline Atributos & Modelo 1 & Modelo 2 & Modelo 3 \\
\hline PM & 27.84 & 39.9 & 30.82 \\
DISTMAR & -0.31 & -0.49 & -1.07 \\
RANUAL & 40.29 & 14.44 & 70.45 \\
UANUAL & 6.98 & -9.01 & -18.65 \\
RSET & -26.12 & 19.62 & -0.6 \\
TJAN & 36.63 & 51.79 & 18.91 \\
TJUL & -17.49 & -38.65 & -10.23 \\
LATITUDE & - & 18.21 & - \\
DENSIDADE & - & - & -0.07 \\
\hline
\end{tabular}

Fonte: Elaboração dos autores a partir dos coeficientes estimados e apresentados nas Tabelas 1 e 2.

(1) Referem-se às RMs de Belém, Fortaleza, Recife, Salvador, Belo Horizonte, Rio de Janeiro, São Paulo, Curitiba e Porto Alegre.

valor que os trabalhadores atribuem para morar em localidades que tenham uma boa qualidade do ar.

Em adição, os resultados estimados indicam que os trabalhadores preferem morar em localidades próximas ao mar (ver o sinal negativo da variável DISTMAR).

Com relação aos indicadores de precipitação, conforme o modelo 1 sugere, os trabalhadores preferem morar nas regiões metropolitanas com maior índice médio de precipitação anual (RANUAL), mas com menor média de precipitação no mês de setembro (RSET). Contudo, pode-se dizer que esses resultados são contraditórios, pois, contrário do obtido pela estimação da equação hedônica dos salários e aluguéis, no caso de os dois atributos representarem uma amenidade para os trabalhadores, ambos deveriam apresentar o coeficiente negativo, pela estimação da equação dos salários, e o sinal positivo, pela estimação da equação dos aluguéis (ver Tabela 4)

Já a função de preço implícito da umidade relativa do ar (UANUAL), calculada a partir do modelo 1 , sugere que 0 aumento marginal da umidade relativa do ar $(U A N U A L)$ influencia positivamente a função de utilidade dos trabalhadores.

Quanto à temperatura média de janeiro (TJAN), o sinal positivo da função de preço implícito desse atributo, obtido a partir do modelo 1 , sugere que o aumento da temperatura neste mês tem um efeito positivo para o bem-estar dos trabalhadores. Mas, os resultados sugerem que a temperatura média de julho (TJUL) atua como uma amenidade negativa para os trabalhadores, um incremento desse atributo influencia negativamente a função de utilidade dos trabalhadores.

Além disso, de acordo com o modelo 2, os trabalhadores preferem morar nas RMs com as maiores latitudes. E a função de preço implícito estimado da densidade demográfica (DENSIDADE), referente ao modelo 3 , indica que os trabalhadores preferem residir nas RMs com menores densidades demográficas.

De posse dos preços implícitos estimados, é calculado o índice de qualidade de vida proposto por Roback (1982), ordenando-se as regiões metropolitanas de acordo com suas dotações dos atributos locais considerados para o cálculo do índice.

A respeito dos índices de qualidade de vida calculados com base em Roback (1982), vale a ressalva de que interpretações cautelosas devem ser realizadas quanto aos rankings obtidos com base na abordagem hedônica. Primeiro, como já evidenciado, algumas variáveis não apresentaram o sinal esperado e, por isso, tais limitações devem ser levadas em conta para a interpretação dos resultados. Segundo, o índice de qualidade de vida hedônico é uma medida relativa, pois mensura apenas o valor dos atributos locais incorporados no exame 
empírico. Consequentemente, pode haver variabilidade nos rankings, quando são explorados diferentes atributos locais.

Contudo, os rankings obtidos a partir dos três modelos estimados - do modelo 1 , o qual explora apenas atributos de clima, geográfico e da poluição do ar, do modelo 2 , que, além desses atributos, foi adicionada a variável "latitude", e do modelo 3 , com a incorporação da variável "densidade demográfica" - apontaram para a mesma ordenação das duas regiões metropolitanas que ficaram nas primeira e segunda colocações do ranking: do Rio de Janeiro e de Porto Alegre, respectivamente. Quanto às demais regiões metropolitanas, considerando-se o modelo 1, ficaram ordenadas da seguinte forma: RM de Belém em terceiro lugar, seguida pelas de Curitiba, Salvador, São Paulo, Fortaleza, Recife e Belo Horizonte.

Um fato a ser destacado é a baixa variabilidade nas colocações das regiões metropolitanas nos três ranking, com a introdução da variável "latitude", no segundo modelo, e da variável "densidade", no terceiro, apontando os dois últimos modelos para a mesma ordenação das regiões metropolitanas.

A respeito dessa regularidade observada dos resultados, primeiramente pode-se intuir que os atributos, comuns aos quatro modelos, têm um maior peso quando ponderados pela função de preço implícito, para o cálculo do ranking, em relação à latitude (modelo 2), e da densidade demográfica (modelo 3).

Por outro lado, considerando-se o modelo 1 , um resultado mais intuitivo seria que as regiões metropolitanas mais próximas geograficamente e com atributos climáticos mais parecidos ficassem em colocações mais próximas nos rankings. Porém, observando os rankings, percebe-se, por exemplo, que, enquanto a RM de Belém ficou na terceira colocação, a de Fortaleza ocupou o sétimo lugar.

\section{Considerações finais}

O artigo teve como objetivo principal inferir sobre a influência das amenidades naturais nas escolhas locacionais dos trabalhadores das regiões metropolitanas. Além disso, são apresentadas estimativas para a propensão marginal a pagar pelas amenidades locais exploradas na pesquisa, bem como um ranking da qualidade desses atributos para as regiões metropolitanas brasileiras.

Três modelos são estimados. O primeiro considera apenas atributos climáticos, geo-

TABELA 4

Ranking de qualidade de vida hedônico

Regiões metropolitanas do Brasil (1) - 2006

\begin{tabular}{|c|c|c|c|c|c|}
\hline \multicolumn{2}{|c|}{ Modelo 1} & \multicolumn{2}{|c|}{ Modelo 2} & \multicolumn{2}{|c|}{ Modelo 3} \\
\hline IQV & RM & IQV & RM & IQV & RM \\
\hline 1.502 & Rio de Janeiro & -0.243 & Rio de Janeiro & -0.90 & Rio de Janeiro \\
\hline 1.494 & Porto Alegre & -0.262 & Porto Alegre & -0.92 & Porto Alegre \\
\hline 1.468 & Belém & -0.266 & Curitiba & -0.92 & Curitiba \\
\hline 1.466 & Curitiba & -0.304 & Recife & -0.96 & Recife \\
\hline 1.402 & Salvador & -0.319 & Belém & -0.97 & Belém \\
\hline 1.401 & São Paulo & -0.342 & São Paulo & -1.00 & São Paulo \\
\hline 1.395 & Fortaleza & -0.344 & Fortaleza & -1.00 & Fortaleza \\
\hline 1.390 & Recife & -0.391 & Salvador & -1.04 & Salvador \\
\hline 1.204 & Belo Horizonte & -0.543 & Belo Horizonte & -1.20 & Belo Horizonte \\
\hline
\end{tabular}

Fonte: Elaboração dos autores a partir das funções de preço implícito apresentadas na Tabela 3.

(1) Referem-se às RMs de Belém, Fortaleza, Recife, Salvador, Belo Horizonte, Rio de Janeiro, São Paulo, Curitiba e Porto Alegre. 
gráficos e da poluição do ar, variáreis estas comuns aos três modelos. Da mesma forma, um segundo modelo foi estimado adicionando, ao primeiro, a variável "latitude" das regiões metropolitanas e, no terceiro modelo estimado, incluiu-se a variável "densidade demográfica".

De acordo com o modelo de Roback (1982), se o atributo local influencia positivamente a função de utilidade dos trabalhadores, o diferencial do salário com relação a esse atributo deve ser negativo e o diferencial do preço do aluguel com relação ao atributo, positivo. Nesse caso, portanto, a diferença entre os dois diferenciais, do preço do aluguel e do salário, com relação ao atributo local, será positiva, indicando que o atributo é uma amenidade e que os trabalhadores estão dispostos a pagar pelo seu consumo.

Assim, utilizando como referência o modelo 1 , os resultados indicaram que os trabalhadores estão dispostos a pagar para morar em regiões mais próximas à costa, nas RMs com os maiores índices médios de precipitação anual, nas RMs mais úmidas e com as maiores temperaturas médias no mês de janeiro. Por outro lado, os trabalha-

\section{Referências}

BRASINGTON, D.; HITE, D. Demand for environmental quality: a spatial hedonic analysis. Regional Science and Urban Economics, v. 35, n. 1, p. 57-82, 2003.

DOWNES, T.; ZABEL, J. The impact of school characteristics on house prices: Chicago 1987-1991. Journal of Economics, v. 52, n. 1 p. 1-25, July 2002.

EVANS, A. The assumption of equilibrium in the analysis of migration and interregional differences: a review of some recent research. Journal of Regional Science, v. 30, p. 51531, November 1980.

GRAVES, P.; MUESER, P. The role of equilibrium and disequilibrium in modeling regional growth and decline: a critical reassessment. Journal of Regional Science, v. 33, n. 1, p. 69-84, 1993. dores devem ser compensados monetariamente para morar nas RMs com os maiores índices médios de precipitação no mês de setembro e com as maiores temperaturas médias em julho.

Porém, também foram obtidos alguns resultados não esperados, dos sinais dos diferenciais dos salários e dos preços dos aluguéis com respeito aos atributos locais incorporados no exame empírico, o que influenciou no sinal positivo da função de preço implícito da variável "poluição do ar". Contudo, vale ressalvar que tal variável pode estar captando a influência de outras variáveis que devem atuar como amenidades para os trabalhadores.

Desta forma, diante de alguns resultados não esperados, obtidos pela estimação das equações hedônicas dos salários e dos aluguéis, recomenda-se que pesquisas que utilizem a abordagem hedônica, como método de valoração das amenidades, sejam realizadas com cautelas, levando em consideração as limitações impostas pela abordagem para a obtenção do verdadeiro valor que as pessoas estão dispostas a pagar pelas amenidades.

GREENWOOD, M.; GARY, L.; RICKMAN, D.; TREYZ, G. migration, regional equilibrium, and the estimation of compensating differentials. American Economic Review, v. 81 p. 1382-1390, December 1991.

BLOMQUIST, G.; BERGER, M.; HOEHN, J. New estimates of qualiy of life in urban areas. The American Economic Review, v. 78, n. 1, p. 89-107, 1988.

CRAGG, M; KAHN, M. New estimates of climate demand: evidence from location choice. Journal of Urban Economics, n. 42, p. 261-284, 1997.

CROPPER, L.; DECK, L.; KISHOR, N.; MCCONNELL, K. Valuing product attributes using single market data: a comparison of hedonic and discrete choice approaches. The Review of economics and Statistics, v. 75, n. 2, p. 225-232, 1993. 
FREITAS, S.; LONGO, K.; DIAS, M.; DIAS, P. Emissões de queimadas em ecossistemas da América do Sul. Estudos Avançados, v. 19, n. 53, 2005.

FROTA, A. B.; SCHIFFER, S. R. Manual de conforto térmico. 8 ed. São Paulo: Ed. Nobel, 2007.

GYOURKO, J.; KAHN, M.; TRACY, J. Quality of life and environmental comparisons. In: MILLS, E. S.; CHESHIRE, P. (Eds.). The handbook of applied urban economics, 1997. Disponível em: <http://www. newyorkfed.org/research/economists/tracy/ handbook.pdf > . Acesso em: jan. 2008.

GYOURKO, J.; TRACY, J. The structure of local public finance and the quality of life. Journal of Political Economy, v. 99, n. 4, p. 774-806, August 1991.

HARRIGAN, F.; MCGREGOR, P. Equilibrium and disequilibrium perspectives on regional labor migration. Journal of Regional Science, v. 33, n. 1, p. 49-67, 1993.

HERMANN, B.; HADDAD, E. Mercado imobiliário e amenidades: a view through the window. Estudos Econômicos, São Paulo, v. 35, n. 2, p. 237-269, 2005.

JONKER, N. Constructing quality-adjusted price indices: a comparison of hedonic and discrete choice models. ECB, 2002 (Working paper, 172).

LINNEMAN, P.; GRAVES, P. Migration and job change: a multinomial logit approach. Journal of Urban Economics, v.14, p. 263279, 1983.

LOWRY, W. P. Empirical estimation of urban effects on climate: a problem analysis. Journal of Applied Meteorology, v.16, issue 2, p.129-135, Feb. 1977.

MENEZES FILHO, N.; MARCONDES, R.; PAZELLO, E.; SCORZAFAVE, L. Instituições e diferenças de renda entre os estados brasileiros: uma análise histórica. In: XXXIV ENCONTRO NACIONAL DE ECONOMIA, 2006, Salvador. Anais.... São Paulo: Anpec, v. 1, 2006.

MONTE, D. The amenity cost of marginal climate change: the case of Brazil. Yale University, 2004 (Paper of discussion).
ROBACK, J. The value of local urban amenities: theory and measurement. Dissertation (Ph.D). Univ. Rochester, 1980.

Wages, rents and the quality of life. Journal of Political Economic, v. 90, n. 6, p. 1257-1278, December 1982.

ROSEN, S. Hedonic prices and implicit markets: product differentiation in pure competition. Journal Political Economic, v. 82, n. 1 p. 34-55, Jan./Feb. 1974.

ROSEN, S. On a wage based index of urban quality of life. In: MIESZKOWSKI, P.; STRASSHEIM, M. (Eds.). Studies in urban economics. Baltimore: Johns Hopkins University Press, v. II, 1979, p. 74-104.

SCHACHTER, J.; ALTHAUS P. An equilibrium model of gross migration. Journal of Regional Science, v. 29, n. 2, p. 143-159, May 1989.

SILVEIRA NETO, R.; AZZONI, C. Disparidades regionais de renda no Brasil: qual o papel das amenidades? In: IX ENCONTRO REGIONAL DE ECONOMIA. Anais... Anpec Nordeste, 2004.

SONG, Y.; KNAAP, S. New urbanism and housing values: a disaggregate assessment. Journal of Urban Economics, v. 54, n. 2, p. 218-238, September, 2003.

STAURT, G.; MATTEY, J.; WASCHER, W. Compensating differentials and evolution of the quality-of-life among U.S. States. Federal Reserve Bank of San Francisco, June 1996 (Working papers in applied economic theory, 96-07). Disponível em: $<$ http://ideas.repec.org/p/fip/fedfap/96-07. html >. Acesso em: jan. 2008.

TIMMINS, C. Estimating the amenity costs of global warming in Brazil: getting the most from available data. Economic Growth Center, Yale University (Working papers, 809). Disponível em: <http://ideas.repec. org/p/egc/wpaper/809.html>. Acesso em: jan. 2008.

WOOLDRIDGE, J. Econometric analysis of cross section and panel data. 1 ed. Cambridge, Mass.: The MIT Press, 2002. 


\section{Resumen}

¿Los atractivos naturales influencian a los trabajadores en la elección de un lugar? Evidencias en las regiones metropolitanas brasileñas

El artículo presenta evidencias sobre la importancia de las características naturales de las regiones metropolitanas brasileñas en la elección de un lugar para los trabajadores. El análisis se basa en el modelo de elección de lugar de Roback (1982), a partir de éste procede el valor que los trabajadores atribuyen a vivir en lugares que le ofrezcan un buen disfrute de atractivos naturales. Los resultados principales de la investigación indican que los trabajadores están dispuestos a pagar para vivir en las regiones metropolitanas más próximas a la costa, con los mayores índices medios de precipitación anuales, en las regiones metropolitanas más húmedas, y con las mayores temperaturas medias en el mes de enero. Por otro lado, los trabajadores deben ser compensados monetariamente para vivir en las regiones metropolitanas con los mayores índices medios de precipitación en septiembre y con las mayores temperaturas medias en julio.

Palabras-clave: Valoración de los atractivos naturales. Enfoque hedónico. Calidad de los atractivos naturales.

\section{Abstract \\ Do natural amenities affect location choices of workers? Evidence for Brazilian metropolitan regions}

The article shows evidence of the importance of the natural attributes of metropolitan regions (MR) of Brazil in workers' location choices. The analysis is based on the Roback location choice model (1982). The model was used to derive the value placed by workers on living in localities that offer them consumption of natural amenities. The main results of the survey show that workers are willing to pay to live in MRs closer to the sea, with higher annual average rainfall rates, in more humid MRs, or with higher average temperatures in January. On the other hand, the offset for workers to live in MRs with higher average rainfall rates in September or higher average temperatures in July should be monetary compensation.

Keywords: Valuation of amenities. Hedonic approach. Quality of natural amenities

Recebido para publicação em 19/02/2011 Aceito para publicação em 17/05/2011 


\section{Anexo}

TABELA 1

Estatísticas descritivas das médias mensais da temperatura $(\stackrel{\circ}{\circ})$ observadas nas Plataformas de Coleta de Dados (PCD)

Regiões metropolitanas do Brasil - 1990/2006

\begin{tabular}{lccccc}
\hline Regiões metropolitanas & Média & $\begin{array}{c}\text { Desvio } \\
\text { padrão }\end{array}$ & Máximo & Mínimo & $\begin{array}{c}\text { Amplitude } \\
\text { térmica }\end{array}$ \\
\hline Belém & 26,6 & 0,4 & 27,2 & 26,0 & 1,2 \\
Fortaleza & 26,9 & 0,6 & 27,8 & 26,0 & 1,8 \\
Recife & 26,0 & 1,1 & 27,2 & 24,2 & 3,0 \\
Salvador & 25,7 & 1,3 & 27,2 & 23,7 & 3,5 \\
Belo Horizonte & 21,9 & 1,7 & 23,9 & 19,3 & 4,6 \\
Rio de Janeiro & 25,1 & 2,0 & 27,7 & 22,1 & 5,6 \\
São Paulo & 20,2 & 2,3 & 23,1 & 16,8 & 6,3 \\
Curitiba & 17,5 & 2,8 & 21,1 & 13,4 & 7,7 \\
Porto Alegre & 19,6 & 3,9 & 24,8 & 14,0 & 10,8 \\
\hline
\end{tabular}

Fonte: Instituto Nacional de Meteorologia - INMET. Elaboração dos autores.

TABELA 2

Estatísticas descritivas dos índices de precipitação mensais $(\mathrm{mm})$ registrados nas Plataformas de Coleta de Dados (PCD)

Regiões metropolitanas do Brasil - 1990/2006

\begin{tabular}{|c|c|c|c|c|c|c|c|}
\hline \multirow{2}{*}{$\begin{array}{l}\text { Regiões } \\
\text { metropolitanas }\end{array}$} & \multirow{2}{*}{ Média anual } & \multirow{2}{*}{$\begin{array}{l}\text { Desvio } \\
\text { padrão }\end{array}$} & \multicolumn{2}{|c|}{ Mínimo } & \multicolumn{2}{|c|}{ Máximo } & \multirow{2}{*}{ Amplitude } \\
\hline & & & Média & Mês & Média & Mês & \\
\hline Belém & 8,34 & 4,33 & 3,9 & Setembro & 14,59 & Abril & 10,69 \\
\hline Fortaleza & 4,66 & 4,77 & 0,4 & Outubro & 14,5 & Abril & 14,1 \\
\hline Recife & 5,95 & 4,00 & 1,4 & Novembro & 13,84 & Julho & 12,44 \\
\hline Salvador & 5,29 & 2,77 & 1,7 & Dezembro & 9,83 & Abril & 8,13 \\
\hline Belo Horizonte & 4,32 & 4,06 & 0,2 & Julho & 10,98 & Julho & 10,78 \\
\hline Rio Janeiro & 3,49 & 1,61 & 1,2 & Agosto & 6,21 & Janeiro & 5,01 \\
\hline São Paulo & 4,48 & 3,06 & 0,9 & Agosto & 9,15 & Janeiro & 8,25 \\
\hline Curitiba & 4,36 & 1,56 & 2,7 & Maio & 7,48 & Janeiro & 4,78 \\
\hline Porto Alegre & 3,90 & 0,55 & 3,2 & Março & 4,79 & Julho & 1,59 \\
\hline
\end{tabular}

Fonte: Instituto Nacional de Meteorologia - INMET. Elaboração dos autores.

TABELA 3

Dados da insolação, umidade relativa do ar (\%), velocidade do vento $(\mathrm{m} / \mathrm{s})$, do monóxido de carbono (CO) e do material particulado (PM 2.5), registrados nas Plataformas de Coleta de Dados (PCD) Regiões metropolitanas do Brasil - 1990/2006

\begin{tabular}{lccccc}
\hline Regiões metropolitanas & $\begin{array}{c}\text { Média } \\
\text { insolação } \\
\text { diária } \\
\text { (horas) }\end{array}$ & $\begin{array}{c}\text { Umid. relat. } \\
\text { do ar } \\
\text { (\%) }\end{array}$ & $\begin{array}{c}\text { Veloc. do } \\
\text { vento } \\
\text { (m/s) }\end{array}$ & $\begin{array}{c}\text { Monóxido de } \\
\text { carbono } \\
\text { (ppb) }\end{array}$ & $\begin{array}{c}\text { Material } \\
\text { particulado } \\
\text { (ug/m3) }\end{array}$ \\
\hline Belém & 6,10 & 84,36 & 1,73 & 115,32 & 1,64 \\
Fortaleza & 7,81 & 77,65 & 3,02 & 105,50 & 0,56 \\
Recife & 7,04 & 77,85 & 2,80 & 104,10 & 0,41 \\
Salvador & 6,77 & 80,91 & 1,80 & 109,06 & 0,73 \\
Belo Horizonte & 6,70 & 65,87 & 1,65 & 142,03 & 3,89 \\
Rio Janeiro & $(1)-$ & 73,94 & 1,11 & 161,49 & 6,39 \\
São Paulo & 5,07 & 73,87 & 2,45 & 150,85 & 5,30 \\
Curitiba & 5,18 & 80,76 & 2,07 & 177,53 & 8,01 \\
P. Alegre & 5,74 & 76,76 & 1,92 & 152,55 & 5,96 \\
\hline
\end{tabular}

Fonte: Centro de Previsão de Tempo e Estudos Climáticos - CPTEC; Instituto Nacional de Meteorologia - INMET.

(1) Não foi contabilizada a média da insolação porque muitos dados não foram observados na plataforma do Rio de Janeiro. 
